\title{
PERCEPÇÕES DE PROFESSORES DE ENSINO SUPERIOR SOBRE A LITERATURA DE DIVULGAÇÃO CIENTÍFICA
}

\section{University professors' perceptions of the scientific dissemination literature}

\author{
Ricardo Strack ${ }^{1}$ \\ Rochele Loguércio ${ }^{2}$ \\ José Claudio Del Pino ${ }^{3}$
}

Resumo: O uso da divulgação científica como instrumento pedagógico é o tema de nosso trabalho. Partindo da perspectiva de trazer para a educação em ciências e em química a literatura de divulgação científica (LDC) como um veículo para construção do conhecimento escolar e como alternativa ao livro-texto, apresenta-se neste trabalho a percepção de professores de química do Ensino Superior sobre a sua possibilidade de inserção na prática docente com a finalidade de facultar ao professor em formação o conhecimento deste recurso didático às suas aulas e que isso faça parte do currículo.

Palavras-chave: Literatura de divulgação científica. Ensino. Formação de professores.

\begin{abstract}
This paper focuses on the use of scientific dissemination literature as a pedagogical tool. This study departs from the perspective that the scientific dissemination literature (SDL) can be employed in scientific and chemical education as a means of knowledge construction at school and as an alternative to the didactic textbooks. In this sense, this paper presents the perceptions of chemistry professors on the possibility of employing SDL in teaching. The aim is to provide teachers in training with knowledge of how to use this didactical resource in the classroom, suggesting the inclusion of such knowledge in the teachers' training syllabi.
\end{abstract}

Keywords: Scientific dissemination literature. Teaching. Teachers' formation.

\footnotetext{
${ }^{1}$ Licenciado em Química. Mestrando em Educação Química. Técnico em Assuntos Operacionais. Área de Educação Química, Instituto de Química, Universidade Federal do Rio Grande do Sul (IQ/UFRGS). Porto Alegre, RS. Apoio CNPq. <ricstrack@yahoo.com.br>

${ }^{2}$ Licenciada em Química. Doutora em Ciências Biológicas (Bioquímica). Docente, IQ/UFRGS. Porto Alegre, RS. <rochelel@gmail.com>

${ }^{3}$ Químico. Doutor em Engenharia de Biomassa. Docente, IQ/UFRGS. Porto Alegre, RS. <aeq@iq.ufrgs.br>

${ }^{1}$ Av. Bento Gonçalves, n. 9500, sala D114

Campus do Vale - Porto Alegre, RS

91.501-970 
Strack, R.; Loguércio, R.; Del Pino, J. C.

\section{Considerações iniciais}

Desde a famosa proposição da Organização das Nações Unidas para a Educação, a Ciência e a Cultura (Unesco), "Ciência para Todos", pode-se perceber, no cenário nacional e internacional, uma nova temática que ganha espaço nos periódicos científicos do campo das ciências exatas e da vida e seus correlatos campos educacionais: a divulgação científica.

O tema não é elementar, o nascimento de um novo objeto de saber implica o nascimento de novos sabedores e legisladores ${ }^{5}$ e, nesse movimento, evidencia-se a produtividade do campo de várias maneiras: por intermédio de artigos, projetos, mídia, pessoas, atores e autores em várias instâncias das esferas públicas e sociais.

Nessa mobilização e criação do campo, que ora é compartilhado por cientistas, jornalistas, novelistas e, mais recentemente, educadores e educadores em ciências, o Discurso da Divulgação Científica pode ser considerado, no dizer de Grigoletto (2005), um espaço discursivo intervalar. E, nesse espaço discursivo intervalar, encontramos outros conceitos que completam a divulgação científica ou lhe confrontam, seja como for, tais conceitos são correlatos ao discurso da divulgação científica e, em cada conceito, pode-se perceber um entendimento de como e por que a ciência deve chegar à sociedade. Destacaremos três conceitos que participam e são amplamente conhecidos no campo - os de alfabetização científica, divulgação científica e cultura científica:

[...] alfabetización científica (scientific literacy) y alfabetización científica y tecnológica (scientific and tecnological literacy). Se trata de una metáfora que alude a la importancia que tuvo la alfabetización a fines del siglo pasado y que, en el sentido que ahora se le otorga, designa a un conjunto de saberes, de capacidades o de competencias relevantes para comprender y desenvolverse en nuestro mundo actual. Su consecución representaría para la gran mayoría de la población actual lo que supusola alfabetización en el siglo pasado. (FOUREZ, 1997 apud BLANCO LÓPEZ, 2004, p. 74)

La divulgación de la ciencia se puede interpretar de forma general como el proceso por el cual se hace llegar a un publico no especializado y amplio el saber producido por especialistas en una disciplina científica. (CALSAMIGLIA, 1997, p. 1)

\footnotetext{
${ }^{4}$ Aprendemos, com a década de 1960 e com o movimento científico da década de 1970, que uma proposição da Unesco costuma vir acompanhada de capital econômico, social e simbólico, e gera, em suas malhas de poderes/ saberes, uma demanda imediata. Claramente, não podemos dizer se a Unesco gera a demanda ou é por ela gerada, provavelmente, como coloca Popkewitz (1991), a mudança na sociedade esteja imbricada com as necessidades que um texto como o da Unesco produz, e não lhe seja um a priori.

${ }^{5}$ No sentido dado ao termo legislador por Lyotard (1998), ou seja, qualquer pessoa com lugar e autoridade para implementar uma lei.
} 
A expressão cultura científica engloba a ideia de que o processo que envolve o desenvolvimento científico é um processo cultural, quer seja considerado do ponto de vista de sua produção, de sua difusão entre pares ou na dinâmica social do ensino e da educação ou, ainda, do ponto de vista de uma divulgação na sociedade como um todo, para o estabelecimento das relações críticas necessárias entre o cidadão e os valores culturais, de seu tempo e de sua época (SABBATINI, 2003).

Em tais conceitos se percebem as redes de poderes/saberes presentes e os entendimentos de ciência e de sociedade em geral. É possível perceber que o conceito de alfabetização científica traz em seu escopo não apenas uma vontade de distribuir o conhecimento e divulgar a ciência como algo libertador, mas também como algo econômico, político e importante como ferramenta de manutenção de uma sociedade industrializada e tecnológica.

Segundo Shamos (1988), a alfabetização científica é um desafio inalcançável. O ponto- chave da questão está no fato de que a maioria das pessoas pode viver na sociedade virtualmente ignorando a ciência e a técnica, ao mesmo tempo em que desfrutam de todo seu conforto, de forma que a sociedade se isolou da necessidade de saber ou compreender a origem destes avanços. E, mais, o argumento de que a alfabetização científica é necessária para a participação ativa em questões e decisões relacionadas com a ciência e a técnica ignora a realidade de que a carga de conhecimentos necessária para que se alcancem julgamentos independentes se encontra além da capacidade dos cientistas mesmos. Por outro lado, as controvérsias científico-tecnológicas possuem fortes ingredientes emocionais que levam à distorção de juízos, independentemente do grau de alfabetização científica do indivíduo, dado que as emoções entram em conflito com crenças pessoais, políticas ou religiosas (SABBATINI, 2003).

Transcrevemos esse longo trecho do artigo de Sabbatini por duas razões: por ser de uma coerência que desconstroi algumas ilusões sobre o estatuto da ciência e sua necessidade, e, também, por evidenciar a fragilidade do cientista diante das decisões que o mundo "lá fora" exige.

Quanto ao conceito de divulgação científica, pode-se perceber a tentativa de tradução, a primazia de que divulgar a ciência é ao mesmo tempo traduzi-la para uma sociedade que a ignora sem ao menos se dar conta da sua importância. A divulgação da ciência, ao fazer esse papel, se utiliza de uma outra linguagem, distante da linguagem da ciência.

Entende-se, hoje, em algumas pesquisas sobre a constituição de um saber, que a linguagem mais do que explicar as coisas, as cria. Nesse sentido, Lyotard (2000) argumenta que um dos processos de legitimação de um saber é a caracterização de uma linguagem que, ao mesmo tempo, informa e restringe. A ciência como um saber há muito legitimado possui sua própria linguagem. Os locais instituídos de produção e divulgação acadêmicos têm regras específicas de operacionalização dessa linguagem, "jogos de linguagem”, onde "se privilegiam certos tipos de enunciados, por vezes um único, cuja predominância caracteriza o discurso de uma instituição" (LYOTARD, 2000, p. 73).

Ao mesmo tempo, manter uma disciplina científica, com seu código e sua linguagem, exige a formação de iguais em competência. A ciência busca esses possíveis iguais na sociedade em geral e na escola básica: a investigação científica faz um apelo ao ensino como seu complemento necessário. Pois é necessário ao cientista um destinatário que possa, por sua vez, ser um remetente, que seja um parceiro. Da mesma forma, é importante que a sociedade entenda a importância da ciência para ser o seu avaliador e remetente final, mesmo sem conhe- 
cer a linguagem científica. Criam-se mecanismos de linguagem, um discurso intervalar que faz a ponte academia-sociedade-escola.

Ron (2002, p. 1) compreende essa relação ciência/sociedade e suas redes de poder evidenciando que "acceder a semejantes edifícios [edifícios cognitivos erigidos pela ciência], comprender o que dicen y explican, es algo que, como las sociedades actuales saben muy bien, da poder, poder intelectual, político, econômico, industrial e militar". É complexo e paradoxal esse acesso da sociedade à ciência, pois é preciso divulgar os fatos, as obras, os entendimentos da ciência para a sociedade em geral, mas se a sociedade dominar os códigos científicos, a ciência perde seu estatuto de poder. Portanto é preciso informar sem divulgar os códigos, sem empoderar.

O conceito de cultura científica traz uma abordagem mais ampla e de alguma forma, ao considerar a ciência como uma produção cultural, consegue inseri-la na perspectiva da cultura "culta" - ignorá-la é tornar-se inculto. Essa apropriação da ciência como bem cultural da humanidade pode ser entendida como uma imposição de uma cultura de elite para a sociedade em geral. Pode-se, no entanto, entender a ciência não mais como cultura de uma elite, dado que estamos imersos numa cultura científica; inegavelmente, a ciência em nossa sociedade é construtora da cultura de massa, seus códigos podem ser específicos, mas seus efeitos podem ser sentidos diariamente. Efeitos que constroem nosso entendimento de natureza e natural, de ética e de estética, entre tantas questões; os efeitos da ciência ocupam o espaço da nossa vida em sociedade, nossa vida política, nossa casa, nosso quarto, marcam não apenas os modos de vida como os próprios corpos ${ }^{6}$.

Cuidamos, até aqui, de evidenciar alguns conceitos que entendemos como básicos para se empreender uma discussão sobre a Literatura de Divulgação Científica (LDC), e manifestamos alguns entendimentos possíveis sobre os mesmos. As colocações sobre os três conceitos fundamentais que perpassam o espaço discursivo intervalar desse novo campo de saber que é o da divulgação em ciências servem como um breve mapeamento da problemática da legitimidade do saber construído e perpassado nesses lugares.

A divulgação em ciências, a cultura e a alfabetização científicas têm a sociedade como referente. Nosso estudo quer fazer o movimento inverso, quer perceber como a produção textual do espaço discursivo intervalar da divulgação da ciência é entendido, analisado e comentado pelos cientistas/professores que atuam na universidade e na formação de professores, que, em última instância, serão os divulgadores/alfabetizadores/culturalistas das ciências.

Para tanto, utilizamos uma das muitas materialidades de difusão desse discurso científico - a Literatura de Divulgação Científica - como forma de análise na academia. O uso da Literatura de Divulgação Científica (LDC) tem, no nosso entendimento, como base a valorização de práticas que, além de facilitarem a apropriação do saber científico, podem contribuir para a formação de hábitos e atitudes que permanecerão mesmo após o período de formação educacional (ALMEIDA e RICON, 1993). Para nós, a educação não pode ignorar a influência e o impacto que a divulgação científica tem sobre os estudantes e, assumida a idéia de que o ensino

\footnotetext{
${ }^{6}$ A discussão sobre a mudança na nossa sociedade e que se manifesta nos nossos corpos pode ser melhor entendida no texto de Sibilia (2002).
} 
Percepções de professores de Ensino Superior...

de ciências, segundo Blanco López (2004) pode e deve se ocupar da divulgação científica, é necessário contemplar distintas perspectivas, sendo a LDC, como recurso didático, uma delas.

\section{A pesquisa: literatura, saberes e sujeitos}

Nosso grupo de pesquisa tem investigado livros de literatura científica ${ }^{7}$, partindo da perspectiva de que a literatura científica tem se mostrado como uma das fontes de conhecimento tanto entre alunos como entre professores, passando a ocupar um espaço importante de produção do saber. No entanto, essa possibilidade literária da ciência e sua linguagem não entram tranquilamente na vida acadêmica, sendo frequentes as críticas às aventuras científicas em outras mídias, bem como a aventura de não-cientistas como divulgadores da ciência.

Essa pouca aceitabilidade pode significar a ampliação da distância entre formação de professores e práticas escolares, pois o incentivo ao trabalho com os documentos midiáticos além de fazer parte de políticas educacionais governamentais é uma das mais efetivas proposições de mudança metodológica no ensino de ciências desde a década de 1990. Dado que os livros didáticos tendem a trazer um cotidiano limitado a temas específicos e em forma demonstrativa, os professores buscam a mídia como uma das formas mais recorrentes de associar cotidiano e escola.

Assim, não faz sentido a universidade ignorar essa demanda e deslegitimar a literatura científica sob a perspectiva da problemática da linguagem; cabe, por outro lado, fazer uma análise rigorosa desses materiais e sua potencialidade de utilização na formação inicial e continuada de professores. Sabe-se que alguns movimentos se fizeram nesse sentido por meio da análise de revistas científicas oferecidas ao público em geral - como, por exemplo: Superinteressante, Galileu, Ciência Hoje, Scientific American - Edição Brasil etc - visando o entendimento da linguagem e dos conceitos que permeiam o trabalho das revistas e a "veracidade" de seus conceitos. Porém, a literatura científica na forma de narrativa ainda continua sendo ignorada pelas pesquisas, que acabam por deslocá-la para um lugar do entretenimento, e não da formação.

Nesse processo, é importante investigar como os professores universitários entendem, trabalham ou conhecem essa literatura científica, dado que as licenciaturas devem ser pensadas na perspectiva de proporcionar uma formação inicial que contemple conhecimentos específicos da área, mas que não se distancie da promoção de estudos direcionados para a escola e que entendam as necessidades de manter uma atualização no ensino, mesmo que para isso se faça necessário repensar a sua prática.

Por sua vez, a literatura científica tem, como em qualquer outro lugar, produções interessantes e produções com problemas sérios, dentre outros os conceituais, e desta forma

\footnotetext{
${ }^{7}$ Estamos entendendo como literatura científica as produções literárias sobre a ciência que primam por uma linguagem narrativa própria dos textos ficcionais. Assim, têm-se produções essencialmente ficcionais que usam analogias para se entender a ciência, bem como histórias das ciências com algumas passagens explicitamente ficcionais.
} 
sua utilização implica seu conhecimento e análise. Assim, nossa proposta de pesquisa pretende investigar justamente as percepções dos professores universitários que lecionam na licenciatura frente a esses dois aspectos pouco analisados pela pesquisa acadêmica. Tais aspectos nos parecem importantes na construção de uma licenciatura que conheça e possa interferir positivamente no uso desta forma narrativa, prazerosa e atraente de ensinar ciências, que pode ajudar ou atrapalhar a construção do saber científico nas universidades e/ou escolas.

Um primeiro movimento de pesquisa foi conhecer e analisar alguns livros de LDC. Para tanto, buscou-se selecionar livros que são (ou cumprem função) ${ }^{8}$ de divulgação científica, voltados para a temática da natureza corpuscular da matéria que é, segundo Benarroch (2000), um dos conteúdos de grande contribuição às linhas de pesquisa sobre as concepções dos alunos. Assim, utilizaram-se livros disponíveis nas editoras e que contemplavam a temática relacionada, juntando-se a esses algumas aquisições em LDC da Área de Educação Química AEQ (Departamento de Química Inorgânica - Instituto de Química - UFRGS) 9

Um segundo movimento da pesquisa foi a relação recepção-crítica dos textos por alguns professores universitários que atuam na licenciatura em química no RS, mas fazem pesquisa em diferentes áreas da química. Foi entregue, para leitura, um livro para cada professor. Realizaram-se, neste movimento, dez entrevistas relativas à análise de dez livros de LDC (Tabela I).

Tabela 1. Os livros.

\begin{tabular}{llc}
\hline \multicolumn{1}{c}{ Título em português } & \multicolumn{1}{c}{ Autor } & Leitor \\
\hline O Tio Alberto e o Mundo dos Quanta & Stannard (1994) & A \\
O Mágico dos Quarks & Gilmore (2002) & B \\
Tio Tungstênio & Sacks (2002) & $\mathrm{C}$ \\
Bohr - o arquiteto do átomo & Abdalla (2003) & $\mathrm{D}$ \\
O átomo & Kahn (1964) & $\mathrm{F}$ \\
O sonho de Mendelelev & Strathern (2002) & $\mathrm{G}$ \\
Alice no país do Quantum & Gilmore (2002) & $\mathrm{H}$ \\
Lavoisier - o estabelecimento da química moderna & Filgueiras (2002) & $\mathrm{I}$ \\
Viagem ao reino da Química & Veado (1930) \\
Dos Raios-X aos Quarks & Segré (1987) & $\mathrm{J}$ \\
\hline
\end{tabular}

No primeiro momento, os professores tiveram um tempo para a leitura dos livros. Posteriormente, foram realizadas entrevistas semiestruturadas com os mesmos, registradas em meio magnético e transcritas para análise. As entrevistas foram pautadas pelas seguintes questões, das quais os entrevistados já tinham prévio conhecimento (Quadro 1).

\footnotetext{
${ }^{8}$ Assumimos aqui a postura de Ron (2002), de que a literatura que trata da História da Ciência também cumpre função de divulgação científica.

${ }^{9}$ As análises realizadas por nosso grupo de pesquisa podem ser encontradas em trabalhos publicados como Strack, Loguercio e Del Pino (2005a e 2005b).
} 
Percepções de professores de Ensino Superior...

Quadro 1. As questões.

1 - Como você vê a divulgação da ciência por meio deste tipo de literatura?

2 - Você julga ela importante na compreensão pública da ciência?

3 - Como você avalia o uso deste tipo de livro na sala de aula? Você o usaria na sua aula? Em que momento? De que forma?

4 - Quais as contribuições deste tipo de livro/literatura para a formação geral e/ou científica de estudantes do Ensino Fundamental e Médio?

5 - O que você destacaria como mais importante/interessante neste livro?

6 - O conhecimento da História da Ciência é importante do ponto de vista do Ensino de Graduação? Qual sua justificativa?

7 - Qual a sua opinião sobre o uso de figuras de linguagem (metáforas, por exemplo) em textos de divulgação científica?

8 - Qual a sua opinião sobre o uso destas mesmas figuras de linguagem em estratégias de ensino na área de conhecimento das Ciências Físicas e Biológicas ou da Química?

9 - A linguagem utilizada pelo autor é adequada para a compreensão do tema abordado no livro? É adequada/correta quanto à área conceitual relativa ao tema do livro?

10 - Há aproximação do conhecimento científico/contexto científico com o cotidiano do leitor? Que tipo de contribuição este texto pode trazer para esta circunstância?

11 - Considerando o fato científico, gerado no contexto da ciência do cientista, é claramente descrito pelo autor para que seja entendido/compreendido num contexto de ciência de senso comum que afeta a qualquer cidadão?

12 - Este livro pode se constituir num elemento motivador do estudante para dar continuidade a seus estudos nesta linha de conhecimento? Poderia influenciar o estudante na opção de uma carreira em área científica da ciência?

13 - Qual o papel destes materiais bibliográficos na divulgação do conhecimento científico, ou da ciência?

14 - Qual o papel destes materiais bibliográficos como facilitadores da compreensão do conhecimento científico ou da ciência?

15 - No seu entendimento, quem prioritariamente deveria exercer o papel de divulgação do conhecimento científico ou da ciência, o cientista, o professor universitário, todos os professores independente do nível de atuação, o jornalista especializado, outro personagem? Justifique.

16 - Em sua opinião, este saber narrativo da ciência apresentado neste livro, é legitimado na academia produtora de conhecimento científico?

17 - Qual o tipo de contribuição que este material bibliográfico pode trazer para a formação de professores de química/ciências? Você utiliza alguma estratégia didática de inclusão destes materiais como contribuição à formação pedagógica de professores?

No entanto, ao transcorrer das entrevistas, os professores eram deixados livres para discutirem as questões que mais lhe interessassem ou das que manifestadamente falavam com aparente propriedade, com o intuito de lhes deixarem à vontade para expressar suas opiniões. A intenção não era esgotar todas as questões uma a uma, e sim possibilitar o afloramento de concepções latentes correlatas a algumas das questões originais. Com base nisto houve a emergência, nas entrevistas dos professores universitários, de três aspectos que discutiremos a seguir.

\section{Legitimidade na autoria}

Os textos de LDC tiveram unanimidade de aceitação, sendo enfatizado o prazer da leitura desses textos pelos professores que entravam em contato com eles pela primeira vez. 
Enfatizamos que essa aceitação é plena como obra literária mas, quando o texto é solicitado a ser analisado em outras perspectivas, como a do ensino, ou como livro didático na universidade, outras variáveis se tornam fundamentais e as problematizações se fazem presentes.

Em nossa pesquisa, a análise da LDC é empreendida por professores que são também cientistas e buscam essa referência no prestígio do autor. As falas destacam o autor do livro evidenciando, como na fala do professor F, sua titulação acadêmica: "O autor é um filósofo e professor de matemática e ele então coloca as coisas bem dentro do espirito da época"; ou então, como a professora J: "ele é um livro escrito por uma pessoa que é um Prêmio Nobel em Física, e ele se propõe a contar uma História da Física, a visão dele da História da Física [...]"

Os entrevistados também recorrem, na apresentação do autor, à sua instituição. Em uma fala representativa deste discurso, o professor B diz: "a primeira coisa que en acho que tinha que colocar é que o autor do livro é um professor de Física, Robert Gilmore, que trabalha inclusive no CERN, Centro Europeu de Pesquisa Nuclear, que é o centro mais avançado em termos de Física das Partículas [...]"; e, quando questionado sobre a visão da Academia sobre os livros de divulgação científica, o professor G fala: "certamente a academia vai ver melhor o Atkins do que o Strathern, porque o Strathern joga em todos os campos, ele joga em todos os campos, então é uma coisa que a pessoa fica com o pé atrás. Ele fala de quimica, mas também fala de Platão, Sócrates, São Tomás de Aquino, Nietz̦sche [...]". Esta última fala evidencia a relação que as ciências têm com a especialização: é importante, na ciência atual, conhecer de forma hermenêutica sobre um tema muito bem definido e finito. A erudição, mesmo quando pensamos em formação de professores, parece ser um excesso, uma falha, uma superficialidade.

A fala do professor $G$ é representativa da valorização dada pelos professores pelo fato de o(s) autor(es) serem ou não pertencentes a determinado grupo de especialistas, o que relembra as observações de Bruno Latour em seu livro "Vida de Laboratório":

Quem fala de ciências conhecendo-as em detalhe e de primeira mão? Os próprios cientistas. Também falam de ciência os professores, os jornalistas, o grande público, só que falam de longe, ou com a incontornável mediação dos cientistas. Para falar das ciências é preciso ser especialista, declara-se de antemão qualquer pesquisa direta de campo. (LATOUR, 1997, p. 25)

Ainda marcando a importância do autor como escritor de LDC, destacamos a fala do professor $\mathrm{A}$, que reage ao ser questionado sobre possíveis erros conceituais presentes em seu livro: "de jeito nenhum... eu até nem me sinto à vontade para corrigir um autor desses".

No entanto, pesquisadores em divulgação da ciência destacam que a necessidade de legitimidade do autor por meio da sua autoridade/competência científica na área a qual está publicando sua obra de divulgação científica é uma questão discutível. Em Crato (2005, p. 9) aparece a ideia de que "há grandes cientistas que são bons divulgadores, mas há muitos outros que serão péssimos comunicadores. Não estão vocacionados para esse trabalho nem o sabem fazer", da mesma forma "há grandes divulgadores que não são cientistas. Um exemplo brilhante é o de Bill Bryson, um escritor que consegue transmitir o fascínio da história da ciência e da investigação científica porque é um grande profissional da escrita que tem consciência dos seus limites [...]" (CRATO, 2005, p. 9). Segundo este autor, o fato de o divulgador não perten- 
cer a um determinado grupo de especialistas não pode ser motivo para desqualificar o seu trabalho, da mesma forma, todo especialista não deve ser obrigado a divulgar o seu conhecimento para o público não-especialista por não dispor de vocação e, sobretudo, de tempo, como veremos mais adiante. Nossa pesquisa mostra que o autor que não traz em sua história uma aproximação forte com a pesquisa científica, seja em que campo for, é passível de ser mais criticado e, portanto, possui menos autoridade na academia.

\section{Importância, relevância e tempo}

Como vimos no tópico anterior, a LDC é adjetivada pelos sujeitos da pesquisa como interessante, prazerosa e com competência reconhecida em função de alguns autores serem cientistas legitimados pela comunidade acadêmica. Coube-nos questionar qual a possibilidade de inserção desses textos como apoio ou construtor de conceitos em sala de aula. Esse questionamento trouxe, para a nossa pesquisa, uma problemática conhecida nos estudos educacionais, que abarca tanto a escola básica como o ensino universitário (graduação, pós-graduação e extensão): a intensificação do trabalho docente e as ferramentas de avaliação e repasse de recursos por agências financiadoras de projetos de pesquisa.

Sabe-se que o professor universitário, para manter uma pesquisa acadêmica, precisa produzir uma série de artigos científicos, além, é claro, de ler outros tantos. Segundo a observação de Latour, "os atores reconhecem que a produção de artigos é a finalidade essencial de sua atividade" (1997, p. 70), essa produção é responsável pela aquisição de capital simbólico e econômico. Sobre a importância da coletividade, Latour argumenta que nada é mais improdutivo para a ciência e, em particular para um pesquisador, que a falta de discussão da sua proposta de construção de um conhecimento científico. Para o pesquisador, é preferível a negação, a recusa, a crítica, seja negativa ou positiva, ao abandono ou desconhecimento por parte de seus pares. A construção de um fato científico é tão coletiva que uma pessoa sozinha apenas constrói sonhos, alegações e sentimentos, mas não fatos (LOGUERCIO, 2004). Quanto ao capital econômico propiciado pela produção de artigos, se deve à avaliação realizada pelos órgãos governamentais de fomento à pesquisa, onde um dos critérios é a publicação de artigos e o impacto dos mesmos.

Nesse sentido trazemos, como exemplo, a fala do professor $\mathrm{H}$, que manifesta suas dificuldades quando questionado sobre a existência de motivação para o uso, na sala de aula, da LDC:

"Não. Não adianta, as pessoas são movidas à publicação em revista de impacto, infelizmente, éo número de artigos multiplicado pelo fator de impacto da revista e a culpa não é das pessoas, as pessoas precisam publicar, tu é respeitado pelo número de artigos que tu tem, não é pelas pessoas que tu formou, pelos alunos que tu teve, pela qualidade da tua aula, não, isto é muito triste, tanto que eu não quero mais dar aula de graduação, quero dar aula de laboratório, pegar dez alunos de laboratório uma vez.por semana e não me incomodar, eu não quero mais disciplina teórica... eu levei para casa ontem quarenta e duas provas para corrigir e trouxe hoje parte corrigida, ninguém mais quer fazer isso, por que? Não te sobra tempo, tempo é precioso: precisa estar orientando aluno para publicar artigo. Infelizmente é assim que funciona". 
$\mathrm{E}$, ainda, como indica o professor C, não basta produzir artigos e publicá-los em revistas de impacto, é necessário também estar atualizado, pois a velocidade de novos conceitos e objetos da ciência é muita grande: "a gente está tão saturado com o volume do que tem obrigação de ler que não dá tempo. Na minha área de pesquisa, se eu não ler 15 artigos por semana, eu estou defasado: eu chego lá e sou confrontado com as coisas da minha profissão e não sel".

A pesquisa é prioridade na vida desses professores/pesquisadores, pois ela implica toda uma gama de recursos e condições de trabalho que, de outra maneira, não seriam possíveis. Os docentes são submetidos a uma sobrecarga de trabalho que Apple (1995) denomina de intensificação ${ }^{10}$, tal sobrecarga atinge o tempo livre das pessoas tanto para viver quanto para conhecer. O desconhecimento dificulta os questionamentos e, ao não se questionar, não se reflete, não se reavalia e não se muda. Entender que as políticas de avaliação das agências de fomento são construídas pelos próprios pesquisadores e, portanto, passíveis de mudança, autoriza uma resistência a essas formas avaliativas. Por outro lado, tanto agências de fomento à pesquisa quanto governo e professores parecem não perceber que a desqualificação no trabalho docente na graduação resulta, a médio prazo, em formação de iguais em incompetência - o inverso da ênfase de Lyotard (2000), segundo o qual é preciso formas iguais em competência para que a pesquisa tenha continuidade e progresso.

À parte as questões do tempo disponível para a preparação de aulas, os professores indicam também como problema o tempo de duração das disciplinas, que, segundo eles, precisam dar conta de um número muito grande de informações em pouco tempo. Essa também é uma abordagem bastante comum e estudada nas pesquisas educacionais. Algumas dessas pesquisas indicam, pelo menos na escola básica, que grande parte dos conteúdos desenvolvidos são inúteis e/ou irrelevantes. No entanto, talvez não se possa dizer o mesmo em relação aos conteúdos de disciplinas universitárias, o que se pode problematizar certamente é a abordagem centrada no conteúdo químico, e não nos conceitos químicos.

Duas falas nos parecem importantes de serem destacadas: a fala da professora A, que manifesta sua preocupação com o tempo do curso, caso o uso da LDC fosse tentado no curso de formação de professores:

"É dificil porque, se en for faz̧er isso na Quimica Geral eu não venço o conteúdo, não que o importante seja vencer o conteúdo, mas o próprio curso se estende, por exemplo, se tu pegas um aluno da licenciatura noturna, ele precisa trabalhar, até que ponto ele tem que estudar e trabalhar para o seu sustento, muitas vez̧es eles casam, tem filhos, como é que a gente vai exigir esta construção que seria tão bonita e tão melhor, mas como é que a gente vai exigir isso [...]"

E a fala da professora J que, ao ser perguntada sobre o uso de literatura na disciplina de físico-química II da licenciatura, explicita, corroborando com a professora A que

10 "A intensificação representa uma das formas pelas quais os privilégios dos trabalhadores/as são degradados". (APPLE, 1995, p. 39) 
Percepções de professores de Ensino Superior...

"é uma disciplina básica [...] e com um volume de conteúdo muito grande [...] ela junta praticamente outras duas disciplinas do curso de Química, a Físico-Química 2 e a Físico-Quimica 3 [...] aí, na medida do possivel, eu procuro [...] mas aí não dá tempo de traz̧er um texto pra ler, en procura trazer mais algumas aplicaçoes, um exemplo, eu uso mais exemplos práticos, aspectos históricos, eu sempre procuro dar no início [...] quando eu vou introduzir um conceito e mostrar em que época isto aconteceu [...] contextualizar um pouco porque estava sendo desenvolvido, não dá pra usar tanto [...]" [referindo-se a LDC].

No entanto, a mesma professora J, em outra disciplina, utiliza LDC, conforme sua fala:

"como eu dou aula pro curso noturno, não adianta eu me iludir que en vou diz̨er "vocês leiam este capitulo e que na próxima aula nós vamos discutir" que eles não tem tempo... alguns lêem, outros não [...] a gente tem que entender que eles não tem tempo pra fazer tanta leitura [...] então eu costumo fazer esta leitura em sala de aula, claro que ai não dá tempo de ler todo o capitulo, às vezes o capitulo é meio extenso [...] mas aí a gente lê algumas partes, eu falo algumas coisas, a gente lê uma outra parte, depois en falo outras [...] e a gente vai discutindo."

A manifestação das professoras representa uma preocupação comum quando se propõe uma nova prática educativa, qual seja, a extensão do curso e o alcance de um conteúdo mínimo ministrado, corroborando nossa expectativa com relação à inclusão da LDC e sua dificuldade de implantação.

\section{Divulgação na mídia, autoridade e responsabilidade}

A mídia sabidamente tem um papel fundamental na construção de sujeitos e na transformação das culturas. Pode-se, hoje, falar de uma pedagogia da mídia ${ }^{11}$ que supera, às vezes, a pedagogia escolar e acadêmica em termos de acesso e de espaço no cotidiano. Os objetos de curiosidade em relação à ciência são gerados nessa relação com as reportagens científicas que aparecem tanto em jornais (impresso, TV, internet) com temas variados e que usam a ciência e seu discurso para divulgar, validar e indicar onde está a "verdade" das coisas, como em revistas, programas e cadernos especializados em temas científicos, o chamado jornalismo científico.

Segundo Teixeira (2002, p. 140): "Se o jornalista que cobre ciência é um bom jornalista, não se preocupem: a qualidade da divulgação científica virá por si”. Esse pensamento não é acompanhado por alguns de nossos entrevistados, na verdade, o jornalismo científico não é um tema em que exista uma unanimidade, até mesmo por que implica o surgimento de um novo sujeito produtor de saber. Grigoletto (2005, p. 44), baseando-se em Foucault, identifica que "o sujeito do saber não é mais o cientista, mas sim o jornalista que assina a matéria (pelo

\footnotetext{
${ }^{11}$ A mídia, segundo Fischer (1997, p. 61), atua "como veiculadora, mas também como produtora de saberes e formas especializadas de comunicar e de produzir sujeitos, assumindo, nesse sentido, uma função nitidamente pedagógica”.
} 
menos, em se tratando da grande mídia), e representa a autoridade que deveria fazer falar a voz da ciência". Delegar poderes não é simples e, como podemos ver nos comentários dos professores entrevistados, existe aprovação e críticas que implicam o espaço de poder de cada um.

Quando perguntados a respeito do papel dos meios de comunicação na divulgação científica, alguns professores manifestaram suas críticas à falta de profissionalismo nesta prática: Professor $\mathrm{H}$ ] "a divulgação científica é feita muito no oba-oba, então tem até jornalista do setor de ciência e tecnologia mas que é um ignorante no assunto, que vai pelo que for dito [...]"; da mesma forma, o [Professor E] "Tu não vai botar como comentarista de economia um cara que não entende nada, agora, na área da ciência, tu não tem muita preocupação, botar para comentar a ciência um cara que tenha formação cientifica $[\ldots . .$.$] .$

Um outro ponto de vista aparece na fala da Professora I: "obviamente, que um cronista, colunista ele não tem o conhecimento, ele só vai poder ser responsável até onde ele sabe, a gente vê seguidamente nestas revistas que as pessoas fazem comentário corrigindo, depois é publicado "o leitor fulano-de-tal lembrou que não é bem assim" e "ai todo mundo tem que ser fiscal...", que pode ser associada à discussão elaborada pelo Professor G:

"eu acho que, por exemplo, não existe 'uma' revista de divulgação científica, mas existem degraus de revistas de divulgação científica, eu acho interessante que tenha uma revista mais 'light' como a Superinteressante, Galileo e que tenha revistas mais pesadas, mais rigorosas, como a Scientific American, como a Ciência Hoje. A existência dos dois planos é muito importante porque incentiva o aluno a subir de um degrau para outro, ou seja, capta primeiro aquele conbecimento básico porque é aquela coisa: se é algum conhecimento que está muito fora da área da pessoa, sei lá, vamos dizer que algum conceito bem especifico dentro da área da medicina, pra nós também é grego, então muito pra nós seria mais interessante pegar uma Superinteressante primeiro, que abordasse este assunto e depois, eventualmente, uma Scientific American, uma Ciência Hoje, se começasse já da parte mais dura, mais hard, não seria muito importante".

A fala do Professor G coincide com a observação de Crato, que escreveu:

Revistas como a Scientific American ou o American Scientist, ou mesmo a parte expositiva da Nature ou da Science, constituem fontes de informação geral para muitos profissionais. A evolução vertiginosa da ciência moderna e a sua extrema especialização levam à necessidade, mesmo para os cientistas, de se actualizarem lendo artigos e revistas que se podem considerar como pertencendo à categoria da divulgação. (CRATO, 2005, p. 6)

Ou seja, a divulgação científica também é fonte de informação para os especialistas.

Esses entendimentos diferentes e que enfocam três perspectivas para se observar o movimento da ciência na mídia são característicos de um campo de saber que se constrói entre dois outros, no caso, os campos do jornalismo e da ciência, e que, ainda, podem servir como base para um terceiro campo, o da educação em ciência. Talvez, como destaca a Professora A, não seja importante o sujeito que produz o discurso sobre os objetos da ciência, mas seu grau de comprometimento com o saber científico sobre esse objeto: "[...] qualquer um, desde que 
Percepções de professores de Ensino Superior...

realmente domine o assunto e seja autoridade no sentido de responsabilidade do que está escrevendo pra falar determinado assunto".

Sabemos, no entanto, que a autoria é importante no universo científico, como vimos neste artigo. Também sabemos que a constituição de uma linguagem é a constituição de um novo espaço de poderes e saberes. Por essas razões, nunca é tranquilo o entrecruzar de fronteiras. Mas a mídia não apenas divulga bem ou mal os fatos científicos, como os utiliza como forma de validação de saberes; e, para além disso, tem a capacidade de dizer, para nossos alunos, o que é importante em termos de ciência - e essa é uma questão muito relevante, pois, como destaca Schmidt (2006), temos de ir além de uma discussão quantitativa e geográfica, é preciso colocar em pauta a qualidade, a consistência da escola e da informação veiculada na mídia. Pois é impossível escapar à presença, à representação da mídia. A mídia deve ser vista aqui como uma dimensão central das nossas experiências enquanto homens e mulheres destes tempos. Experiência não como ação, mas como algo que nos toca, nos afeta, nos constitui.

\section{Considerações finais}

Podemos afirmar que a Literatura de Divulgação Científica é um espaço de divulgação da ciência bem aceito por todos os participantes da pesquisa. Em nossa pesquisa, os professores que conheciam os livros de LDC manifestaram, mais de uma vez, sua boa impressão com relação aos textos, porém seu uso como recurso didático é questionado ou desconhecido. Por sua vez, os professores que não conheciam os livros de LDC manifestaram a boa surpresa de conhecê-los e, da mesma forma, a dificuldade de sua utilização como recurso didático.

Como foi possível observar nas entrevistas, a divulgação da ciência é valorizada no sentido de ser recebida no meio acadêmico como um veículo de informação científica, mas não de formação científica. Dentre as dificuldades para o desenvolvimento destas habilidades, há um obstáculo que dificulta a solidificação de uma prática divulgativa: a falta de compromisso social das instituições de pesquisa e a limitada valorização do potencial educativo da divulgação (VALÉRIO, 2005).

Por outro lado, temos a intensificação do trabalho docente, que aparece de duas formas: na exigência de produção e atualização por parte dos pesquisadores/professores sobre suas próprias práticas acadêmicas, e a necessidade de se trabalhar com muitos conteúdos nas disciplinas do curso de formação de professores. No nosso entendimento, duas colocações extremamente contundentes e bem abordadas por todos os professores pesquisados.

Os dados dessas entrevistas nos mostram, portanto, duas questões importantes: o papel da relação pesquisa-ensino na universidade e um dos modos de apropriação da ciência pela sociedade. As crescentes exigências colocadas pelos órgãos financiadores de pesquisa em relação à produtividade docente e, em paralelo, a falta de docentes nas universidades faz com que os professores, para além de suas pesquisas cotidianas, destinem seus tempos para a leitura e produção de artigos e organização didática de suas disciplinas, não lhes sobrando tempo para questionar o currículo dessas disciplinas. Em nosso entendimento, os modos de avaliação em ação procuram olhar para as universidades e seus docentes, buscando dar conta da pesquisa e pouco ou nada valorizando o ensino e a extensão, como destacado pelo professor $\mathrm{H}$.

437

Ciência \&̊ Educação, v. 15, n. 2, p. 425-42, 2009 
As Diretrizes Curriculares Nacionais para a Formação de Professores de Educação Básica enfatizam uma "flexibilidade necessária, de modo que cada instituição formadora construa projetos inovadores e próprios, integrando os eixos articuladores nelas mencionados"; e, de forma mais específica, o texto complementa: "a flexibilidade abrangerá as dimensões teóricas e práticas, de interdisciplinaridade, dos conhecimentos a serem ensinados, dos que fundamentam a ação pedagógica, da formação comum e específica, bem como dos diferentes âmbitos do conhecimento e da autonomia intelectual e profissional" (BRASIL, 2002, p. 26). Outras considerações das diretrizes referem-se à prática como componente curricular "no interior das áreas ou das disciplinas que constituírem os componentes curriculares de formação", não se limitando às disciplinas pedagógicas, e, uma forma de enriquecimento dessas práticas, é o uso da LDC. Num quadro onde há falta de articulação entre ensino, pesquisa, divulgação e aplicação dos conhecimentos, destes, conforme apontado por Valério (2005), o que apresenta carência maior é o campo da divulgação da ciência, o que, numa sociedade que pretende ser democrática e onde a ciência e a tecnologia ocupam lugar destacado, é faltar com a responsabilidade social na produção do conhecimento científico.

As falas trazem à tona a relação pesquisa-ensino e a contribuição que uma política de 'máquinas de produzir artigos' pode trazer aos cursos de graduação (OLIVEIRA, 2005), além da percepção de investigação, por parte do professor, como algo exclusivamente centrado no laboratório e não aplicável ao ensino, conforme observado por Cachapuz (2002, p. 123) quando escreve a respeito da reflexão sobre a prática docente:

Curiosamente, é o que os professores universitários sempre fizeram, mas em relação à sua aprendizagem, isto é, como investigadores. O que importa aqui é uma mudança de atitude, transferir para o seu ensino as atitudes de reflexão crítica, rigor e persistência que habitualmente têm para com a sua aprendizagem. Reflectir sobre quais os saberes de referência são relevantes, por exemplo para a disciplina que se vai ministrar, realizando uma transposição didáctica que os transforme em objectos de ensino (informação) e de aprendizagem (comunicação). Estes saberes resultam de um sinergismo entre saberes disciplinares e saberes profissionais (epistemologia da prática). Tal reflexão poderá modificar o quadro de referência dominante no ensino universitário, que é o de se reproduzirem métodos e técnicas de ensino, e selecção de conteúdos, a que os docentes foram expostos quando estudantes, e permitir um câmbio da 'equação' dominante de ensino "informação + transmissão = ensino", para a 'equação' alternativa "informação + criação de situações de aprendizagem = ensino".

Ligado às noções de divulgar, alfabetizar e aculturar, há um substrato comum, qual seja, as demandas de uma sociedade tecnológica. Com base nisso, pergunta-se: são estas compatíveis com as respectivas demandas de uma sociedade que anseia ser democrática? E mais: qual o objetivo da divulgação/alfabetização/aculturação? Formar iguais em competência ou tratar a ciência um bem cultural? O modelo que aparece subjacente aos discursos dos professores entrevistados (modelo do déficit) é o correlato do modelo de transmissão-recepção no 
ensino do conhecimento científico: um especialisa (ou portador de conhecimento) transmite informações a um público leigo, uma platéia idealmente passiva (Dickson, 2000). Que camisa de força é essa que prende o aprender de forma unidirecional a uma autoridade ${ }^{12}$ que fala enquanto o Terceiro Estado ${ }^{13}$ se cala?

Uma provável resposta talvez seja a de que esta 'camisa de força' signifique o conjunto das concepções que têm permeado as discussões acerca dos 'fundamentos culturais' da atividade científica frente aos que seriam os 'fundamentos naturais'. Uma dicotomia representada pelas contendas do tipo externalismo/internalismo e cultural/natural. Afinal, defender a ciência enquanto instância cultural não implica necessariamente uma noção menos verticalizada de como se dá a apropriação dos conceitos científicos, tanto na sala de aula quanto sociedade afora, uma vez que esta defesa pode estar pautada por noções dicotômicas de ciência.

Bruno Latour, em seu livro Esperança de Pandora (LATOUR, 2001), define duas concepções de ciência com objetivos políticos totalmente diferentes: a Ciência $n^{\circ} 1$, se referindo à série de impossibilidades inerentes ao acordo modernista que a imagem tradicional da ciência passa, e a Ciência n ${ }^{\circ} 2$.

Tendo sido projetada como arma, essa concepção de Ciência [Ciência $\left.\mathrm{n}^{\circ} 1\right]$ [...] não é utilizável nem para 'tornar a humanidade menos irracional' nem para tornar as ciências melhores. Tem apenas um uso: 'Mantenha a boca fechada' - com o 'você' designando, curiosamente, outros cientistas envolvidos em controvérsias tanto quanto as pessoas em geral. (LATOUR, 2001, p. 296)

Desta forma "para se apreciar devidamente esse trabalho científico a Ciência $\mathrm{n}^{\circ} 1$ é totalmente inadequada, porque o que a Ciência $\mathrm{n}^{\circ} 2$ precisa, contrariamente à Ciência no 1 , é de muitas controvérsias, problemas, assunção de riscos e imaginação [...]" (LATOUR, 2001, p. 297-8).

A noção ${ }^{\circ} 2$ ele nomeia também de Pesquisa: é justamente na atividade da pesquisa que a ciência é melhor entendida. O princípio construtor do conhecimento científico que, curiosamente, como aponta Cachapuz (2002), poderia ser o princípio educativo na atividade didática, fica reservado ao laboratório. Além disso, a construção colaborativa do conhecimento é outra noção que faz parte da Pesquisa e que poderia definir uma forma de pensar tanto a divulgação/alfabetização/aculturação quanto a prática em sala de aula.

Em suma, cadeiras, disciplinas, cátedras poderão ser instituídas acerca da divulgação do conhecimento científico, mas, se a prática em sala de aula, nos diversos níveis, corroborar as tendências aqui apresentadas pelos professores, a compreensão pública da ciência será só mais uma instância de saber com seus especialistas/divulgadores e sua noção de público emvias-de-ser-alfabetizado/aculturado, em suma, inculto.

\footnotetext{
12 As auctoritates, como refere Ribeiro (1999).

${ }^{13}$ Terceiro Estado é uma analogia de Latour (2001) para retratar criticamente a noção de que o demos carece de moralidade tão facilmente quanto lhe falta conhecimento epistêmico.
} 
Strack, R.; Loguércio, R.; Del Pino, J. C.

Essas questões, no entanto, apesar de serem extremamente relevantes, só podem ser analisadas se levadas em conjunto com outras questões globais, práticas e imediatas colocadas textualmente pelos professores, como a intensificação do trabalho docente. Seja qual for a perspectiva dos governos ou docentes com relação à pesquisa, extensão e ensino, os tempos dos professores estão limitados e sua sobrecarga de trabalho invade a vida privada, uma intensificação naturalizada nas práticas e discursos cotidianos.

A LDC exige um certo tempo, uma certa conversão do olhar e uma mudança filosófica e curricular. Entende-se a dificuldade de sua inserção mais claramente depois dessas entrevistas, mas também se percebe que existe uma motivação gerada por essas leituras, que alguns docentes, como a professora J, já utilizam os livros nas aulas em que o "tempo" permite. Podese dizer que o estudo sobre a LDC, tanto com relação a sua produtividade quanto a sua inserção na educação, é um potencial lugar de pesquisa e um possível espaço para inserção de novos saberes com ênfase no conceito, e não no conteúdo. Nosso grupo de pesquisa avalia esses e outros passos na legitimação de saberes e toma o espaço discursivo intervalar como uma forma estética e histórica de aprendizagem em química.

\section{Referências}

ABDALLA, M. C. Bohr: o arquiteto do átomo. São Paulo: Odysseus, 2003.

ALMEIDA, M. J. P.; RICON, A. E. Divulgação científica e texto literário - uma perspectiva cultural em aulas de física. Caderno Catarinense de Ensino de Física, Florianópolis, v. 10, n. 1, p. 7-13, 1993.

APPLE, M. Trabalho docente e textos: economia política das relações de classe e de gênero em educação. Porto Alegre: Artes Médicas, 1995.

BENARROCH, A. El desarrolo cognoscitivo de los estudiantes en el área de la natureza corpuscular de la matéria. Ensenãnza de las Ciências, Barcelona, v. 18, n. 2, p. 235-46, 2000 .

BLANCO LÓPEZ, A. Relaciones entre la educación científica y la divulgación de la ciencia. Eureka, Vigo, v. 1, n. 2, p. 70-85, 2004.

BRASIL. Ministério da Educação. Diretrizes Curriculares Nacionais para a Formação de Professores de Educação Básica. Resolução CNE/CP 1, de 18 de fevereiro de 2002. Brasília, 2002.

CACHAPUZ, A. F. A universidade, a valorização do ensino e a formação dos seus docentes. In: SHIGUNOV NETO, A.; MACIEL, L. S. B. (Orgs.). Reflexões sobre a formação de professores. São Paulo: Papirus, 2002. p. 115-39.

CALSAMIGLIA, H. Divulgar: itinerários discursivos del saber. Revista Quark, Barcelona, n. 7, p. 1-8, 1997.

CANDOTTI, E. Ciência na Educação Popular. In: BRITO, F.; MASSARANI, L; MOREIRA; I. C. (Orgs.). Ciência e público: caminhos da divulgação científica no Brasil. Rio de Janeiro: Casa da Ciência/UFRJ, 2002. p. 15-24. 
Percepções de professores de Ensino Superior...

CRATO, N. Questionando algumas idéias feitas sobre a investigação, a divulgação, e o ensino. 2005. Disponível em: <http://pascal.iseg.utl.pt/ ncrato/Expresso/

Gulbenkian.pdf>. Acesso em: 08 jun. 2007.

DICKSON, D. Science and its public: the need for a "third way". Social Studies of

Science, Nova York, v. 30, n. 6, p. 917-24, 2000.

DUARTE, J. Da divulgação científica à comunicação. 2003. Disponível em: < http:// www.abjc.org.br/artigos/art_241103.htm>. Acesso em: 04 abr. 2006.

FILGUEIRAS, C. L. Lavoisier: o estabelecimento da química moderna. São Paulo: Odysseus, 2002.

FISCHER, R. M. B. O estatuto pedagógico da mídia: questões de análise. Educação \& Realidade, Porto Alegre, v. 22, n. 2, p. 59-80, 1997.

GILMORE, R. O mágico dos Quarks. Trad. Maria Luiza X. de A. Borges. Rio de Janeiro: Jorge Zahar, 2002.

Alice no país do Quantum. Trad. André Penido. Rio de Janeiro: Jorge Zahar, 1998.

GRIGOLETTO, E. O discurso de divulgação científica: um espaço discursivo intervalar. 2005. 269f. Tese (Doutorado) - Programa de Pós-Graduação em Letras, Instituto de Letras, Universidade Federal do Rio Grande do Sul, Porto Alegre, 2005.

KAHN, F. O átomo. Trad. Francisco J. Buecken. 7. ed. São Paulo: Melhoramentos, 1964.

LATOUR, B. A esperança de Pandora. Bauru: EDUSC, 2001.

Vida de laboratório: a produção dos fatos científicos. Rio de Janeiro:

Relume-Dumará, 1997.

LOGUERCIO, R. Q. Da arquitetura dos textos à eloqüência dos lugares. Revista Ensaio, Belo Horizonte, v. 6, n. 1, p. 1-21, 2004.

LYOTARD, J.-F. A condição pós-moderna. 5. ed. Rio de Janeiro: José Olympio, 2000.

MACEDO, B.; KATZKOWICZ, R. Educação científica: sim, mas qual e como? In: MACEDO, B. (Org.). Cultura científica: um direito de todos. Brasilia: Unesco, 2003. p. 67-86.

OLIVEIRA, F. P. Nos submundos da educação. Revista Espaço Acadêmico, Maringá, n. 54, 2005. Disponível em: <http://www.espacoacademico.com.br/054/

54pc_oliveira.htm>. Acesso em: 08 jun. 2007.

POPKEWITZ, T. S. Reconstituindo o professor e a formação de professores. Revista Brasileira de História da Educação, Campinas, n. 2, p. 59-77, 2001.

RIBEIRO, R. J. Não há pior inimigo do conhecimento que a terra firme. Tempo Social, v. 11, n. 1, p. 185-95, 1999. 
Strack, R.; Loguércio, R.; Del Pino, J. C.

RON, J. M. S. Historia de la ciencia y divulgación. Revista Quark, Barcelona, n. 26, p. 1-2, 2002. Disponível em: < http//:www.prbb.org/quark/26/default.htm>. Acesso em: 22 ago. 2009.

SABBATINI, M. Museus e centros de ciência virtuais: uma nova fronteira para a cultura científica. Comciência, Campinas, n. 45, p. 1-6, 2003.

SACKS, O. Tio Tungstênio: memórias de uma infância química. Trad. Laura Teixeira Motta. São Paulo: Companhia das Letras, 2002.

SCHMIDT, S. Em pauta: a aliança mídia e educação. UNIrevista, São Leopoldo, v. 1, n. 3, p. 1-8, 2006.

SEGRÈ, E. Dos raios-X aos quarks-físicos modernos e suas descobertas. Brasília: Unb, 1987.

SHAMOS, M. H. Science literacy is futile: try science appreciation. The Scientist, Philadelphia, v. 18, n. 9, 1988.

SIBILIA, P. O homem pós-orgânico: corpo, subjetividade e tecnologias digitais. Rio de Janeiro: Relume Dumará, 2002.

STANNARD, R. O tio Alberto e o mundo dos quanta. Lisboa: Edições 70, 1994.

STRACK, R.; LOGUERCIO, R. Q.; DEL PINO, J. C. Os conceitos estruturantes da literatura de divulgação científica como contribuição ao perfil conceitual químico dos alunos. In: ENCONTRO DE DEBATES SOBRE O ENSINO DE QUÍMICA, 25., 2005, Ijuí. Anais... Ijuí, 2005a. 1 cd-rom.

;______ Literatura científica e perfil conceitual químico dos alunos. In: ENCONTRO NACIONAL DE PESQUISA EM ENSINO DE CIÊNCIAS, 5., 2005, Bauru. Caderno de Resumos... Bauru: Abrapec, 2005b. v. 5. p. 1-12.

STRATHERN, P. O sonho de Mendeleiev: a verdadeira história da química. Trad. Maria Luiza X. de A. Borges. Rio de Janeiro: Jorge Zahar, 2002.

TEIXEIRA, M. Pressupostos do jornalismo de ciência no Brasil. In: BRITO, F.;

MASSARANI, L; MOREIRA; I. C. (Orgs.). Ciência e público: caminhos da divulgação científica no Brasil. Rio de Janeiro: Casa da Ciência/UFRJ, 2002. p. 133-41.

UNESCO. O que é? O que faz?. Disponível em: <http://www.unesco.org.br>. Acesso em: 24 ago. 2009.

. Seminário Internacional Ciência de Qualidade para Todos. 2004. Disponível em: <http://cienciaparatodos.unesco.org.br>. Acesso em: 08 jun. 2007.

VALÉRIO, M. A emergência da divulgação científica e o papel das universidades públicas brasileiras. Ciência \& Comunicação, Bauru, v. 2, n. 2, p. 1, 2005.

VEADO, W. Viagem ao reino da Química. 2. ed. São Paulo: Editora do Brasil, 1930.

Artigo recebido em outubro de 2008 e aceito em junho de 2009. 